\title{
Theoretical Investigation of the Sliding Instability and Caving Depth of Coal Wall Workface Based on the Bishop Strip Method
}

\author{
Chao Li, Tianhe Kang (iD, Xiaopo Li, Ligong Li, Xiaoyu Zhang, and Runxu Zhang \\ Key Laboratory of In Situ Property-Improving Mining of Ministry of Education, Taiyuan University of Technology, \\ Taiyuan 030024, Shanxi, China \\ Correspondence should be addressed to Tianhe Kang; tylgdxcks@163.com
}

Received 18 March 2019; Revised 19 August 2019; Accepted 22 August 2019; Published 8 September 2019

Academic Editor: Jian Ji

Copyright (C) 2019 Chao Li et al. This is an open access article distributed under the Creative Commons Attribution License, which permits unrestricted use, distribution, and reproduction in any medium, provided the original work is properly cited.

As mining height increases, the influence of coal wall caving on safety production becomes stronger. There is no systematic and effective method to analyse the risk of coal wall caving and its slip caving depth. First, this paper established the Bishop mechanical model of sliding instability of coal wall, and then it deduced the general equation of a safety factor for every slip surface, which can be used to judge the stability of the coal body on the slip surface. Moreover, taking the 8102 workface in the Wulonghu Mine, China, as an example, this paper evaluated the calculation method of slip surface safety factor in detail and obtained the critical slip surface position and the maximum slip depth of a coal wall. Overall, the results showed that the maximum slip depth based on the Bishop strip method is more consistent with the measured data compared with other methods and thus has strong significance and practical engineering value for selecting the most suitable method and its parameters of regulating coal wall caving.

\section{Introduction}

Thick coal seams account for a large proportion of China's coal resources, and fully mechanized mining with large mining height is the main mining method for $3.5 \sim 8.2 \mathrm{~m}$ thick coal seams $[1-3]$. However, as mining height increases, the pressure on the workface is more and more intense, such that coal wall caving becomes one of the main factors restricting safe and efficient production [4-6]. Severe coal wall caving not only affects the normal production of the workface but also threatens the life and safety of miners [7]. Therefore, controlling coal wall caving has become a key technical issue for fully mechanized mining with large mining heights that has attracted the attention of scholars and engineers. Fu et al. [8] established the coal wall excavation unloading effect model by using the unloading rock mass mechanics theory and the fracture mechanics theory to analyse the coal wall instability mechanism. The research results show that cracks in the coal wall would change into mixed mode cracks under the effects of the unloading stress field. Pang and Wang [9] divided the process of hard coal seam rib spalling into tensile cracking damage and sliding instability based on analysing the effect of the stress path in the process of rib spalling and established the tensile cracking-sliding mechanical model of rib spalling for hard and thick coal seams. Hua and Xie [10] found that the stress state of the coal wall after excavation changes from a three-direction stress state to a two-direction stress or onedirection stress state. Yan et al. [11, 12] used the theory of the "pressure bar" to analyse the deflection characteristics of a coal wall with good integrity. As a result, it is concluded that the part that is most prone to cave is in the middle and upper parts of the coal wall. Yuan et al. [13] built a mechanical model of wedge-shaped sliding coal body of a coal wall workface and analysed the key factors of the sliding instability of a wedgeshaped sliding coal body. Wang et al. $[14,15]$ simplified the trace of coal wall caving from the arc type to the oblique straight line type and considered the caving coal body as a triangular block. Lastly, combined with the safety margin criterion, an equation for judging whether coal wall caving is generated is obtained. Yao et al. [5, 16-19] analysed the factors influencing coal wall caving, including coalface depth, mining height, panel advance velocity, coal strength, and coal seam dip angle. According to these factors, a series of methods for regulating coal wall caving are proposed, including optimizing the production process, optimizing the hydraulic support system, water injection, and wood-bolt reinforcement. 
In summary, the existing research results are mostly focused on analysing the mechanisms of the coal wall caving, the forms of coal wall caving, the factors affecting coal wall caving, and the technical measures to prevent and control coal wall caving. However, an effective method for analysing the coal wall slip risk and the coal wall caving depth has not been found. This status directly limits the accurate determination of the method and its parameters for controlling the coal wall. In view of the above engineering problems, this paper draws on Bishop's strip method, which is commonly used in slope stability analysis, and applies the Bishop method to the analysis of the coal wall stability of a workface. Considering the roof pressure, the safety factor of any slip surface of a coal wall of the workface can be calculated by the Bishop method, and the exact value of the maximum caving depth can be obtained. This research can provide a theoretical basis for the determination of the methods and their parameters for controlling coal wall caving in a large mining height workface.

\section{Method Introduction}

The Bishop strip method $[20,21]$ is a slope stability analysis method proposed by Professor A. W. Bishop of Imperial College London in the 1950s. Based on the Mohr-Coulomb criterion, the Bishop method assumes that the sliding surface of the slope is a circular arc surface and the sliding body is vertically divided into several vertical soil strips. At the same time, the method also assumes that the antisliding safety factors on the sliding surface of each soil strip are the same and are equal to the average safety factor of entire sliding surface. The Bishop strip method is widely used in solving the safety factor of slope stability engineering because the calculation results are more realistic [22-25].

The coal body near the coal wall of the workface is ruptured due to the abutment pressure, and the shear strength is greatly reduced. Coupled with the cutting disturbance of the shearer drum, the coal body easily slips along a "sliding surface" that is inclined or approximates a circular arc, as shown in Figure 1. In addition, field test results show that this form of coal wall caving accounted for more than $75 \%$ of the total number of working face cavings $[13,26]$. Therefore, coal wall caving can be regarded as the mechanical process of the sliding coal body sliding along an arcshaped sliding surface through the foot of the coal wall. Considering the roof pressure, the Bishop method is used to establish an improved mechanical model of the coal wall caving, and the slip surface safety factor is calculated. According to the calculation result of the safety factor, the stability of the coal body on the slip surface can be judged.

\section{Calculation of the Safety Factor of a Coal Wall Slip Surface}

3.1. Calculation of Safety Factor of Coal Wall Slip Surface during Horizontal Mining. When the length of the workface is much larger than the caving depth, the workface per unit length can be treated according to the plane strain problem. Using the Bishop strip method principle, a simplified

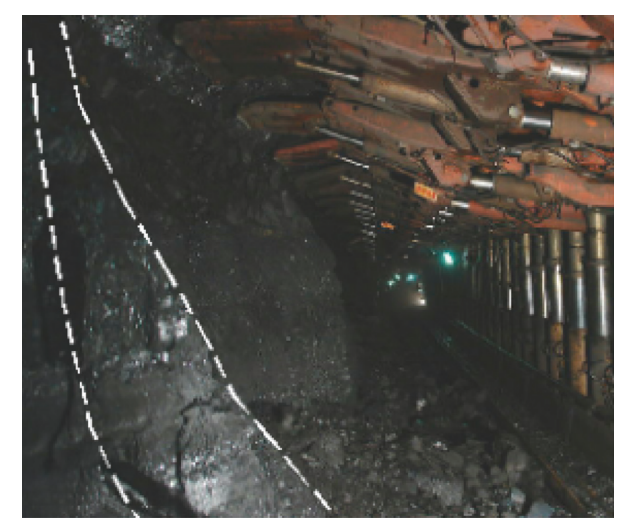

FIGURE 1: The field photo of coal wall caving.

mechanical model of the coal wall slip caving is established, as shown in Figure 2(a). Suppose that the slip surface $A B$ is a circular arc surface with $O$ as the centre, the radius of the arc is $R$, the distance between the centre, $O$, the roof is $y$ at the top of the roof, point $A$ is at the foot of the coal wall, point $B$ is on the contact surface between the coal seam and the roof, $A C$ is the height of the workface, and the distance $d$ of $B C$ is defined as the slip depth of the slip surface, $A B$. The slip caving body, $A B C$, is divided into $k$ vertical coal bars.

According to the force characteristics of the coal wall, the $m$-th coal strip is taken for force analysis, as shown in Figure 2(b). $F_{m}$ is the normal force on the contact surface between the roof and the coal strip; $x_{m}$ is the horizontal distance from the centre, $O$, to $F_{m}$, that is, the force arm of $F_{m}$ to $O ; s_{m}$ is the horizontal distance from the centre, $O$, to the centre line of the coal strip; $f_{m}$ is the frictional resistance of the roof to the coal strip; $y$ is the vertical distance from the centre, $O$, to $f_{m}$, that is, the force arm of $f_{m}$ to $O ; Y_{m}, Y_{m+1}$ and $X_{m}, X_{m+1}$ are the tangential force and normal force between adjacent coal strips, respectively; $W_{m}$ is the self-weight of the coal strip; $N_{m}$ is the normal force on the slip surface of the bottom of the coal strip; $T_{m}$ is the tangential force on the slip surface; $\alpha_{m}$ is the angle between the horizontal direction and the tangent line of the slip surface at the bottom of the coal strip; $l_{m}$ is the length of the bottom of the coal strip along the tangential direction; and $h_{m}$ is the height of the coal strip.

Use $K$ to indicate the safety factor on the slip surface $A B$, and then

$$
K=\frac{\tau_{f}}{\tau},
$$

where $\tau_{f}$ is the average shear strength along the entire slip surface and $\tau$ is the shear stress along the entire slip surface.

When $K>1$, the coal body is stable; when $K<1$, the coal body is unstable; and when $K=1$, the coal body is in a critical instability state.

According to the Mohr-Coulomb criterion, the average shear strength along the entire slip surface $A B$ is

$$
\tau_{f}=c+(\sigma-\mu) \tan \varphi
$$

where $c$ is the coal body cohesion, $\sigma$ is the normal stress on the shear plane, $\mu$ is the pore water pressure, and $\varphi$ is the internal friction angle of the coal body. 


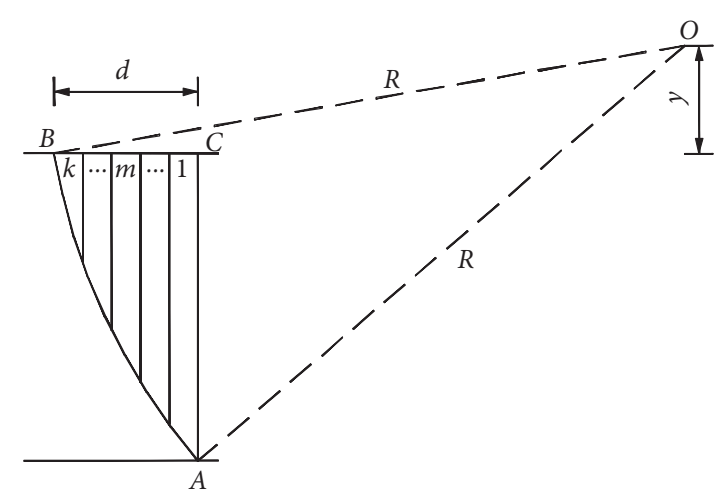

(a)

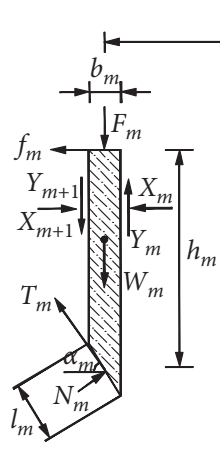

$s_{m} x_{m}$<smiles>[O-][Ca]</smiles>

(b)

FIgURE 2: The Bishop mechanical model of sliding instability of coal wall.

The pore stress, $\sigma_{0}$, is assumed to be zero because the coal body is on the workface; thus, the above equation is simplified to

$$
\tau_{f}=c+\sigma \tan \varphi
$$

The Bishop strip method assumes that $\tau$ is balanced with the tangential force $T_{m}$ on the slip surface, i.e,

$$
\begin{aligned}
T_{m} & =\tau l_{m}=\frac{\tau_{f}}{K} l_{m}=\frac{1}{K}(c+\sigma \tan \varphi) l_{m} \\
& =\frac{1}{K}\left(c l_{m}+N_{m} \tan \varphi\right) .
\end{aligned}
$$

According to the vertical balance condition of the $m$-th coal strip, equation (5) can be obtained:

$$
F_{m}+W_{m}+Y_{m}=N_{m} \cos \alpha_{m}+T_{m} \sin \alpha_{m}+Y_{m+1} .
$$

Substituting equation (4) into equation (5),

$$
N_{m}=\left(F_{m}+W_{m}+Y_{m}-Y_{m+1}-\frac{c l_{m} \sin \alpha_{m}}{K}\right) \frac{1}{\zeta_{m}},
$$

where $\zeta_{m}=\cos \alpha_{m}+\left(\tan \varphi \sin \alpha_{m} / K\right)$.

When the sliding body reaches the limit equilibrium state, the sum of the torque of the coal strip to the centre, $O$, of the slip surface should be zero. At this point, the force between the adjacent coal strip should be regarded as the internal force and will cancel each other out:

$$
\sum F_{m} \cdot x_{m}+\sum W_{m} \cdot s_{m}-\sum f_{m} \cdot y-\sum T_{m} \cdot R=0
$$
(7):

Equations (4) and (6) can be substituted into equation

$$
K=\frac{\sum 1 / \zeta_{m}\left[c b_{m}+\left(F_{m}+W_{m}+Y_{m}-Y_{m+1}\right) \tan \varphi\right]}{\sum\left(F_{m}\left(x_{m} / R\right)+W_{m}\left(s_{m} / R\right)-f_{m}(y / R)\right)} .
$$

Equation (8) is a general expression of the safety factor of the slip surface calculated by Bishop's strip method. In this equation, $Y_{m}$ and $Y_{m+1}$ are unknowns. To find $K$, the $Y_{m}-$ $Y_{m+1}$ value must be estimated, but Bishop proved that if $Y_{m}-Y_{m+1}=0$, the error caused is only $1 \%$; therefore, it is assumed that the vertical shear forces on both sides of the coal strip are equal, i.e., $Y_{m}=Y_{m+1}$. Substituting $s_{m}=x_{m}=$
$R \sin \alpha_{m}$ into equation (8), the simplified Bishop safety factor $K$ expression is obtained:

$$
K=\frac{\sum 1 / \zeta_{m}\left[c b_{m}+\left(F_{m}+W_{m}\right) \tan \varphi\right]}{\sum\left(F_{m} \sin \alpha_{m}+W_{m} \sin \alpha_{m}-f_{m}(y / R)\right)},
$$

where $F_{m}=q_{m} \cdot b_{m}$, in which $q_{m}$ is the vertical stress acting on the coal strip by the roof; $W_{m}=\gamma b_{m} h_{m}$, in which $\gamma$ is the bulk density of the coal strip; and $f_{m}=\tan \varphi F_{m}$, in which $\tan \varphi$ is the frictional resistance coefficient.

\subsection{Calculation of the Safety Factor of a Coal Wall Slip Surface} during Up-Dip/Down-Dip Mining. The Bishop mechanical model of up-dip and down-dip mining, when the coal seam dip angle is $\beta$, is shown in Figures 3(a) and 3(b).

At this time, the safety factor, $K$, expression of the slip surface $A B$ is

$$
K=\frac{\sum 1 / \zeta_{m}\left[\mathrm{cb}_{m}+\left(F_{m} \cos \beta+W_{m}-f_{m} \sin \beta\right) \tan \varphi\right]}{\sum\left(F_{m}\left(x_{m} / R\right)+W_{m} \sin \alpha_{m}-f_{m}(y / R)\right)},
$$

where $f_{m}=q_{m} b_{m} \cos \beta$.

$$
x_{m}=R \sin \left(\alpha_{m}-\beta\right)+h_{m} \sin \beta .
$$

When the workface uses up-dip mining, $\beta$ takes a positive value; when the workface uses down-dip mining, $\beta$ takes a negative value; and when $\beta=0$, equation (10) is reduced to equation (9).

Equation (10) is a general equation for calculating the safety factor, $K$, of a coal wall slip surface by the simplified Bishop strip method. Since the right-hand side of the equation also contains $K$, equation (10) needs to be solved by an iterative method. First, assume a $K$ value to find $\zeta_{m}$, and then substitute $\zeta_{m}$ into equation (10) to find $K$. If this $K$ value does not match the assumed value, re-substitute the $K$ value into $\zeta_{m}$ and re-substitute $\zeta_{m}$ into equation (10) to obtain a new $K$ value. Repeat these steps until the assumed $K$ value is close to the obtained $K$ value. Generally, $K=1$ is assumed first. For the convenience of the calculations, the $\zeta_{m}$ value can be directly found by the values of $\alpha_{m}$ and $\tan \varphi / K_{m}$, as shown in Figure $4[20,21]$. 


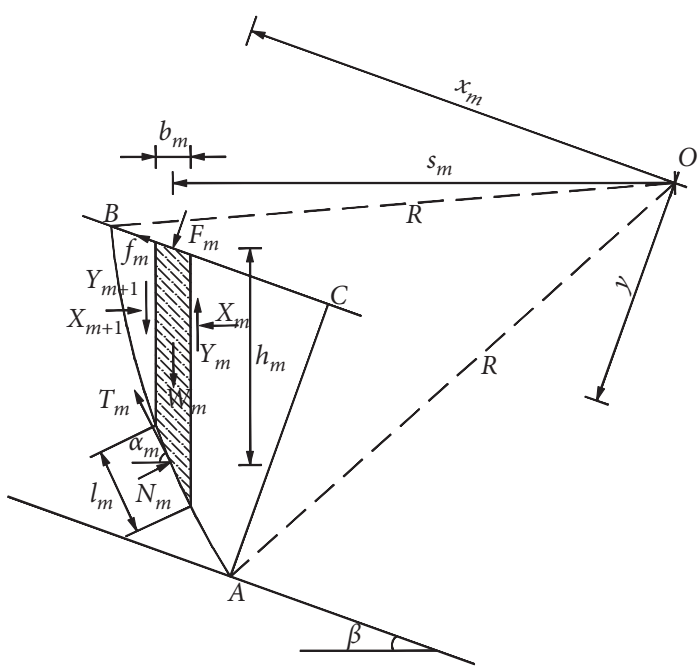

(a)

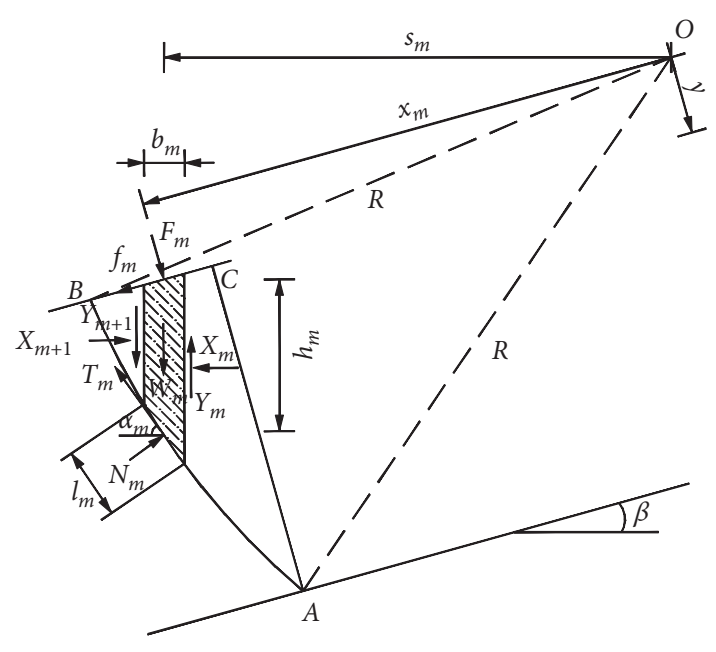

(b)

Figure 3: The Bishop mechanical model of up-dip and down-dip mining when coal dip is $\beta$.

\section{Field Application}

The 8102 workface of the Wulonghu Coal Mine is a monoclinic structure with N-S-trending and E-W-tendency. The dip angle is $5^{\circ} \sim 25^{\circ}$, with an average value of $18^{\circ}$, which is a moderately inclined coal seam. The dip length of the working face is $156-233 \mathrm{~m}$, the strike length is $623-802 \mathrm{~m}$, the mining height is $4.1 \mathrm{~m}$, and the burial depth is approximately $600 \mathrm{~m}$. Fully mechanized mining with a large mining height is used for full thickness mining, and the method of all roof caving is used to deal with the roof. The bulk density, $\gamma$, of the coal body is $14.0 \mathrm{kN} / \mathrm{m}^{3}$, the cohesion, $c$, is $1.0 \mathrm{MPa}$, and the internal friction angle, $\varphi$, is $25^{\circ}$.

4.1. Determination of the Slip Surface Location. To find the position of the critical slip surface with the safety factor $K=1$, several slip surfaces of several different positions should be assumed first. Calculating every safety factor for each slip surface by equation (9), the critical slip surface is the slip surface whose $\mathrm{K}$ value is equal to or closest to 1 . It can be seen in Figure 2 and equation (9) that the arc surface of the crossing point, $A$, is determined by the two parameters of the sliding arc radius, $R$, and the centre height, $y$, so that different values of $R$ and $y$ are combined to obtain a plurality of slip surfaces.

Through a field measurement, the maximum caving depth is $d \leq 1.9 \mathrm{~m}$, and the minimum caving depth in the workface that affects the normal production is $d \geq 0.7 \mathrm{~m}$. The radius of the slip surface is estimated to be $12 \sim 20 \mathrm{~m}$ from the caving depth and the height of the coal seam $(4.1 \mathrm{~m})$; therefore, the radius $R_{j}(j=1,2, \ldots, 6)$ values are $12 \mathrm{~m}$, $14 \mathrm{~m}, 16 \mathrm{~m}, 18 \mathrm{~m}$, and $20 \mathrm{~m}$, respectively. When the radius $R$ of the slip surface is determined, the height of the centre of the circle is larger, and the depth of the determined slip surface is larger. When the height of the centre of the circle is $6.5 \mathrm{~m}$, the minimum depth of the determined slip surface is $1.954 \mathrm{~m}$, which is larger than the maximum caving depth of

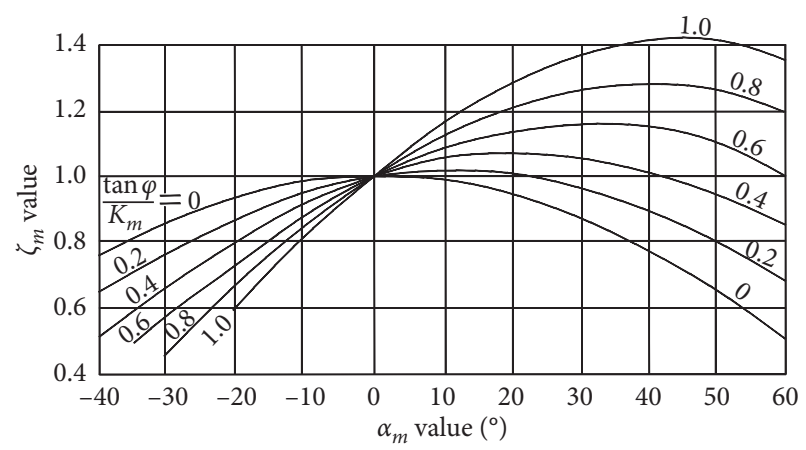

Figure 4: The curve of $\zeta_{m}$ value.

the field measured value. Therefore, the height $y_{i}$ $(i=1,2, \ldots, 5)$ values of the centre of the circle are $0.5 \mathrm{~m}$, $2 \mathrm{~m}, 3.5 \mathrm{~m}, 5 \mathrm{~m}$, and $6.5 \mathrm{~m}$, respectively. Therefore, $25 \mathrm{slip}$ surfaces of $A B_{i j}$ are obtained from the combination of $R_{j}$ and $y_{i}$, and the slip depths of each slip surface are shown in Table 1 .

4.2. Calculation of Safety Factor $K_{i j}$. According to the mining height and the laws of strata behavior, it is estimated that the maximum slip depth of the coal wall is $1.4 \sim 1.9 \mathrm{~m}$. According to the engineering characteristics of the coal wall caving and the reinforcement methods of the coal wall, the prediction accuracy of the maximum slip depth is $0.2 \mathrm{~m}$. The Bishop strip method is used to divide the coal body of each slip surface into vertical coal strips with widths of $b_{m}=0.2 \mathrm{~m}$. Figure 5 shows the coal strip division corresponding to the slip surface determined by $R_{3}=18$ and $y_{3}=3.5 \mathrm{~m}$. A total of 7 coal strips are divided, and their geometric parameters are shown in Table 2.

Coal wall caving generally occurs in the plastic zone, and the values of the normal stress, $q_{m}$, on the contact surface between the roof and the coal strip can be directly calculated by equation (12) [27], and the results are shown in Table 2. 
TABle 1: The depth of slip surfaces.

\begin{tabular}{lccccc}
\hline \multirow{2}{*}{$R_{j}(\mathrm{~m})$} & \multicolumn{5}{c}{$y_{i}(\mathrm{~m})$} \\
& 0.5 & 2 & 3.5 & 5 & 65 \\
\hline 12 & 0.906 & 1.498 & 2.197 & 3.086 & 4.462 \\
14 & 0.768 & 1.255 & 1.798 & 2.438 & 3.254 \\
16 & 0.668 & 1.071 & 1.510 & 1.999 & 2.568 \\
18 & 0.590 & 0.954 & 1.340 & 1.761 & 2.238 \\
20 & 0.530 & 0.853 & 1.192 & 1.555 & 1.954 \\
\hline
\end{tabular}

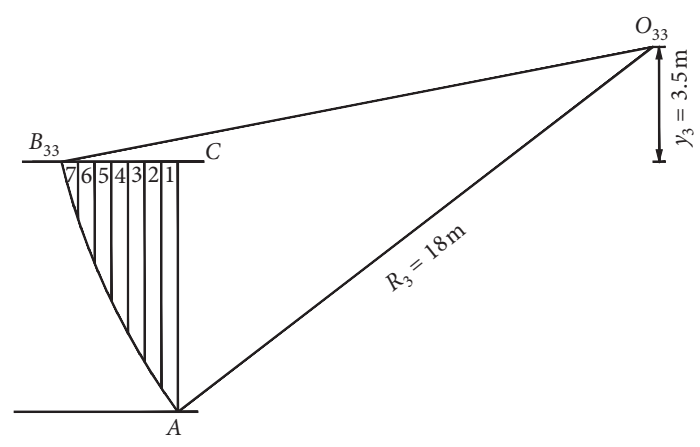

Figure 5: The coal band division.

TABLE 2: The geometric parameters of coal band and the calculation results of $q_{m}$.

\begin{tabular}{lccc}
\hline Number of coal strip $(\mathrm{m})$ & $h_{m}(\mathrm{~m})$ & $\alpha_{m}\left({ }^{\circ}\right)$ & $q_{m}(\mathrm{MPa})$ \\
\hline 1 & 3.880 & 66 & 3.36 \\
2 & 3.420 & 67 & 4.21 \\
3 & 2.918 & 69 & 6.40 \\
4 & 2.367 & 71 & 7.79 \\
5 & 1.572 & 73 & 9.42 \\
6 & 1.045 & 75 & 11.35 \\
7 & 0.3 & 78 & 13.62 \\
\hline
\end{tabular}

$q_{m}=-\frac{c}{\tan \varphi}+\left(\frac{1+3 \theta}{1-3 \theta} p+\frac{c}{\tan \varphi}+\frac{2 \varepsilon}{1-3 \theta}\right) e^{(2 \tan \varphi(1+3 \theta) / M(1-3 \theta)) g_{m}}$,

where $c$ is the coal body cohesion, MPa; $\tan \varphi$ is the friction coefficient of the contact surface of the coal seam and the roof; $p$ is the horizontal thrust of the sidewall guard plate, which is not considered here; $M$ is the thickness of the coal seam, $m ; g_{m}$ is the distance of the coal strip from the edge of the coal wall, $m$; and $\theta=\sin \varphi / \sqrt{3\left(3+\sin ^{2} \varphi\right)}$ and $\varepsilon=\sqrt{3} c \cos \varphi / \sqrt{3+\sin ^{2} \varphi}$ are generalized von Mises criterion coefficient.

Substituting the geometric parameters and mechanical parameters of the coal strip into equation (9), the $K_{33}$ value is solved iteratively, and the safety factor on the slip surface is 0.896. Similarly, the safety factors of other slip surfaces can be calculated. Figure 6 shows the iterative curve of the safety factor $K_{i 3}$ values of the five slip surfaces determined by radius $R_{3}=18 \mathrm{~m}$ and $y_{i}=0.5 \mathrm{~m}, 2 \mathrm{~m}, 3.5 \mathrm{~m}, 5 \mathrm{~m}$, and $6.5 \mathrm{~m}$. It can be seen from the figure that when the centre height, $y$, is $5 \mathrm{~m}$, or $6.5 \mathrm{~m}$, the safety factors of the determined slip surfaces $A B_{43}$ and $A B_{53}$ are all greater than 1, which indicates

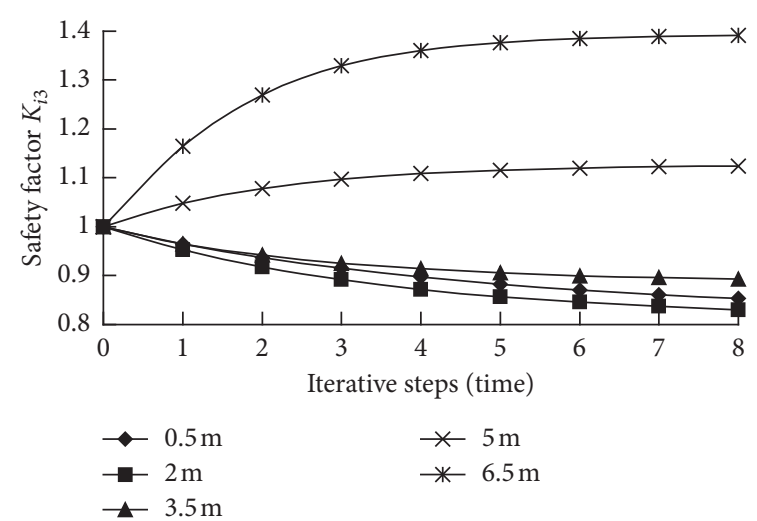

Figure 6: The iterative curve of the safety factor.

that the possibility of the coal wall sliding down along these slip surfaces is small; when $y$ is $0.5 \mathrm{~m}, 2 \mathrm{~m}$, or $3.5 \mathrm{~m}$, the safety factors of the determined slip surfaces $A B_{13}, A B_{23}$, and $A B_{33}$ are less than 1 , which indicates that the possibility of the coal wall sliding down along the slip surface is great.

The safety factors of the 25 slip surfaces of $12 \mathrm{~m}, 14 \mathrm{~m}$, $16 \mathrm{~m}, 18 \mathrm{~m}$, and $20 \mathrm{~m}$ and $y_{i}=0.5 \mathrm{~m}, 2 \mathrm{~m}, 3.5 \mathrm{~m}, 5 \mathrm{~m}$, and $6.5 \mathrm{~m}$ combinations are shown in Table 3 .

The change contours of the safety factor, $K$, with the slip arc radius, $R$, and the centre height, $y$, are shown in Figure 7. It can be seen that the contour line of $K=1$ is a continuous and smooth curve, which indicates that the safety factors of a series of slip surfaces are equal to 1 . The $K$ value is generally small in the lower part and large in the upper part, and the slip surface safety factor determined by $R$ and $y$ corresponding to the coordinates of any point at the bottom of the curve $K=1$ is less than 1 . According to the positional characteristics of the slip surfaces determined by $R$ and $y$ shown in Figure 7, it is shown that the safety factor increases with the increase of the slip surface slip depth in an up-dip mining workface.

4.3. Determination of the Maximum Caving Depth. It is known from Figure 7 that there are many slip surfaces with a safety factor of $K=1$, so it is necessary to determine the location of the critical slip surface with the maximum slip depths, and then the maximum caving depth can be obtained. The change rules of the safety factor, $K$, with slip arc radius, $R$, and centre height, $y$, are fitted to the $K$ surface in Figure 8 by using MATLAB software. The change rules of the slip depth with slip arc radius, $R$, and centre height, $y$, are fitted to the $d$ surface. A continuous and smooth $K_{\mathrm{cr}}$ curve is formed by intersecting the plane of safety factor $K=1$ with the $K$ curved surface, projecting the $K_{\mathrm{cr}}$ curve onto the $d$ surface to obtain a spatial $d_{\text {cr }}$ curve, finding the maximum $F$ point on the $d_{\mathrm{cr}}$ curve and obtaining $F$ coordinates (17.96, $4.20)$. When the radius of the coal wall slip surface is $17.96 \mathrm{~m}$ and the centre height is $4.20 \mathrm{~m}$, the slip surface is the farthest critical slip surface from the coal wall.

From Figures 7 and 8, the overall trend is that the smaller the coal wall caving depth is, the smaller the coal wall safety factor is and the more unstable the coal wall is. So, the 
TABLE 3: The calculation results of safety factors of 25 slip surfaces.

\begin{tabular}{|c|c|c|c|c|c|}
\hline \multirow{2}{*}{$R_{j}(\mathrm{~m})$} & \multicolumn{5}{|c|}{$y_{\mathrm{i}}(\mathrm{m})$} \\
\hline & 0.5 & 2 & 3.5 & 5 & 65 \\
\hline 12 & 0.597 & 0.777 & 1.055 & 1.749 & 3.508 \\
\hline 14 & 0.678 & 0.840 & 1.053 & 1.574 & 2.142 \\
\hline 16 & 0.767 & 0.877 & 1.117 & 1.514 & 2.198 \\
\hline 18 & 0.853 & 0.830 & 0.896 & 1.129 & 1.391 \\
\hline 20 & 0.864 & 0.992 & 1.210 & 1.560 & 2.174 \\
\hline
\end{tabular}

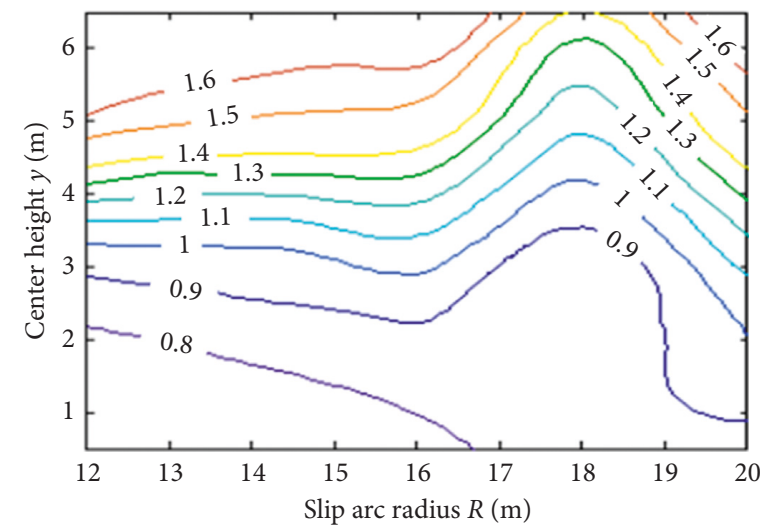

Figure 7: The contour of the safety factors of the slip surfaces.

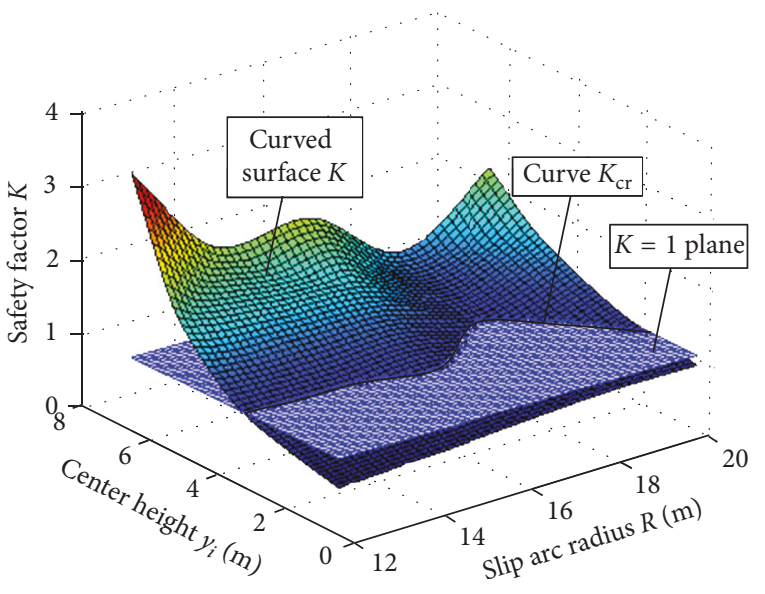

(a)

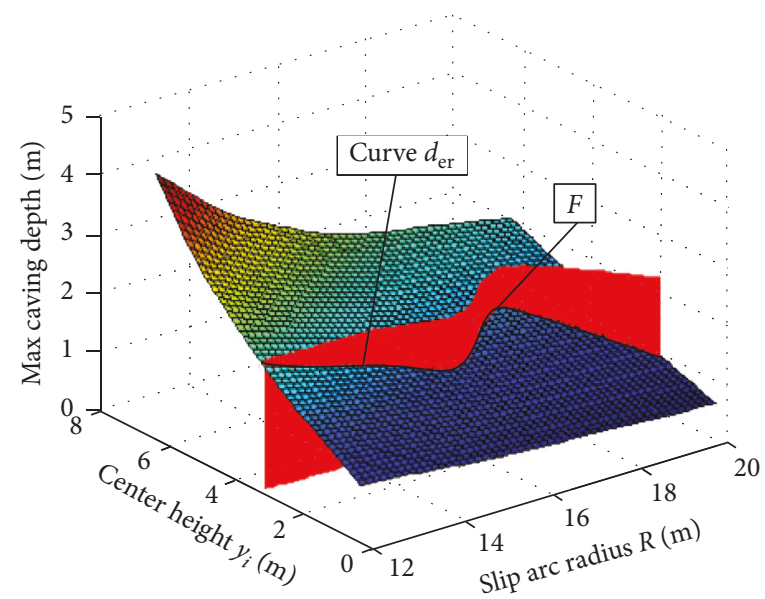

(b)

FIgURE 8: The determination of the critical slip surface.

farthest critical slip surfaces divide the coal body in front of the coal wall into two areas, as shown in Figure 9. The safety factors of the slip surfaces in area (1) are less than or equal to 1 , which indicates that the coal body may easily slip along the slip surface of a certain $K<1$ in this area. Additionally, the coal body in this area may easily be disturbed by a coal cutter, so it is prone to local caving. The safety factors of the slip surfaces in area (2) are greater than 1, which indicates that the coal body will not slide along a slip surface in this area. Therefore, the slip surface $A B$ is the critical slip surface of the coal wall, and the maximum coal wall slip depth is $1.63 \mathrm{~m}$. Based on this, the control method and parameters of the coal wall can be designed accurately.
4.4. Comparative Analysis of Prediction Accuracy. In references $[10,28]$, based on the Mohr-Coulomb strength theory, the equations for calculating the maximum coal wall caving depths for compression-shear-type failure and sliding-type failure are (13) and (14), respectively:

$$
\begin{aligned}
& \Delta \alpha=M \tan \left(45^{\circ}+\beta-\frac{\varphi}{2}\right), \\
& \Delta \alpha=M \tan \left(90^{\circ}+\beta-\varphi\right),
\end{aligned}
$$

where $M$ is the thickness of the coal seam, $m ; \beta$ is the coal seam dip angle, and $\varphi$ is the internal friction angle of the coal body. 


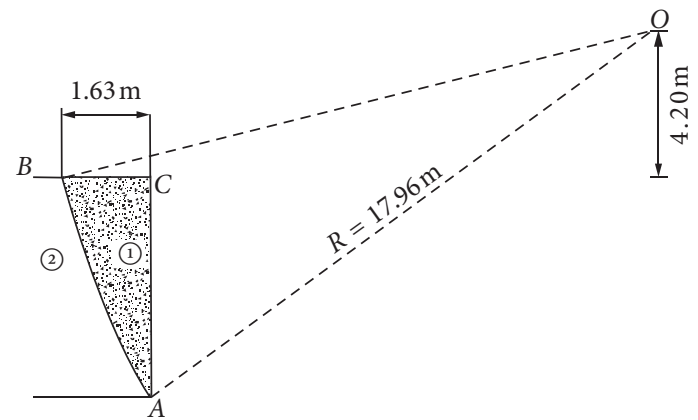

FIgURE 9: The schematic of coal wall safety partition.

TABLE 4: Comparison of calculated and measured values of each method.

\begin{tabular}{lcc}
\hline Types of methods & $\begin{array}{c}\text { Maximum } \\
\text { caving } \\
\text { depth }(\mathrm{m})\end{array}$ & $\begin{array}{c}\text { Difference from } \\
\text { measured } \\
\text { value }(\mathrm{m})\end{array}$ \\
\hline $\begin{array}{l}\text { Average value of field } \\
\text { measurement }\end{array}$ & 1.82 & 0 \\
Compression-shear method & 4.96 & 3.14 \\
Previous sliding method & 33.37 & 31.55 \\
Bishop strip method & 1.63 & 0.19 \\
\hline
\end{tabular}

Based on the aforementioned 8102 workface of the Wulonghu Coal Mine as background, the maximum depth is calculated by using equations (13) and (14), respectively, and compared with the actual field measurement, and the accuracy of each method is analysed. The results are shown in Table 4.

Table 4 shows that the maximum coal wall caving depth obtained according to formula (13) is $4.96 \mathrm{~m}$, which is $3.14 \mathrm{~m}$ from the measured value. The maximum coal wall caving depth obtained according to formula (14) is $33.37 \mathrm{~m}$, which is $31.55 \mathrm{~m}$ different from the measured value, indicating that the formula is not suitable for predicting the coal wall caving depth of the large mining height; the maximum coal wall caving depth obtained by the Bishop strip method proposed in this paper is $1.63 \mathrm{~m}$, which is only $0.19 \mathrm{~m}$ away from the measured value, indicating that the formula predicts accurately.

\section{Conclusions and Discussion}

(1) According to the mechanical characteristics of a coal wall with a large mining height workface, the mechanical model of the coal wall caving is established using the Bishop strip method, and the solution equation of the safety factor $K$ of the coal body on the slip surface is obtained.

(2) In up-dip workface, the smaller the coal wall caving depth is, the smaller the coal wall safety factor is and the more unstable the coal wall is.

(3) Taking workface 8102 of Wulonghu Coal Mine as an example, the safety factor, $K$, of the assumed slip surface is calculated and the critical slip surface position of slip coal caving is obtained. As a result, the maximum slip caving depth is $2.2 \mathrm{~m}$, which is closer to the measured results than the calculation results of the existing compression-shear-type failure equation and sliding-type failure equation. This paper mainly addresses the slip-type coal caving that is common in fully mechanized mining having large mining heights, so these research results cannot explain the phenomenon of swallow-tail-type coal caving and so on. Otherwise, in the derivation of the safety factor equation of the slip surface, the influences of the initial support force and the thrust of the sidewall guard are not taken into account. In the future, research in these areas needs to be further strengthened.

\section{Data Availability}

Our data are from the filed case. The calculation parameters are based on geological data of the 8102 workface in the Wulonghu Coal Mine of China. All initial data of the workface are described in detail in Section 4 of this paper.

\section{Conflicts of Interest}

The authors have no conflicts of interest.

\section{Authors' Contributions}

C. L. completed the establishment of the Bishop mechanical model of coal wall sliding instability and the derivation of the coal wall safety factor, $K$. In the case analysis, X. L. calculated the depth of the coal wall caving depth and compared it with the traditional calculation method. T. K. put forward the innovation and research direction of the article and played a corrective role in the whole process of the paper. All authors gave final approval for publication.

\section{Acknowledgments}

This study was supported financially by the National Natural Science Foundation of China (U1810102).

\section{References}

[1] B. Huang, H. Li, C. Liu, S. Xing, and W. Xue, "Rational cutting height for large cutting height fully mechanized top-coal caving," Mining Science and Technology (China), vol. 21, no. 3, pp. 457-462, 2011.

[2] G. F. Wang, X. Y. Li, C. C. Zhang et al., "Research and development and application of set equipment of $8 \mathrm{~m}$ large mining height fully-mechanized face," Coal Science \& Technology, vol. 45, pp. 1-8, 2017.

[3] S. L. Yang, D. Z. Kong, J. H. Yang et al., "Coal wall stability and grouting reinforcement technique in fully mechanized caving face during topple mining," Journal of Mining \& Safety Engineering, vol. 32, pp. 827-833, 2015.

[4] H. Q. Zhou, C. J. Hou, X. K. Sun et al., "Solid waste paste filling for none-village-relocation coal mining," Journal of China University of Mining \& Technology, vol. 33, pp. 154-158, 2004. 
[5] Q. Yao, X. Li, B. Sun et al., "Numerical investigation of the effects of coal seam dip angle on coal wall stability," International Journal of Rock Mechanics and Mining Sciences, vol. 100, pp. 298-309, 2017.

[6] A. Asadi, K. Shahriar, K. Goshtasbi et al., "Development of a new mathematical model for prediction of surface subsidence due to inclined coal-seam mining," Journal-South African Institute of Mining and Metallurgy, vol. 105, no. 1, pp. 15-20, 2005.

[7] Y. Yuan, S. H. Tu, X. G. Zhang et al., "Mechanism and control technique of rib spalling disaster in fully-mechanized mining with large mining height in soft coal seam face," Disaster Advances, vol. 6, pp. 92-98, 2013.

[8] B. J. Fu, M. Tu, and M. Z. Gao, "Study on unloading instability model of working face with large mining height," Journal of Mining \& Safety Engineering, vol. 34, no. 6, pp. 1128-1133, 2017.

[9] Y. H. Pang and G. F. Wang, "Hydraulic support protecting board analysis based on rib spalling "tensile cracking-sliding" mechanical model," Journal of the China Coal Society, vol. 42, no. 8, pp. 1941-1950, 2017.

[10] X. Z. Hua and G. X. Xie, "Coal wall spailing mechanism and control technology of fully mechanized high cutting longwall coal mining face," Coal Science \& Technology, vol. 36, no. 9, pp. 1-3, 2008.

[11] S. H. Yan and X. W. Yin, "Discussing about the main theoretical problems of long wall with top coal caving," Journal of Coal Science \& Engineering, vol. 33, no. 5, pp. 481-484, 2008.

[12] X. W. Yin, S. H. Yan, and Y. An, "Characters of the rib spalling in fully mechanized caving face with great mining height," Journal of Mining \& Safety Engineering, vol. 2, 2008.

[13] Y. Yuan, S. H. TU, X. T. Ma et al., "Coal wall stability of fully mechanized working face with great mining height in "three soft" coal seam and its control technology," Journal of Mining \& Safety Engineering, vol. 29, no. 1, pp. 21-25, 2012.

[14] J. C. Wang, Y. Yang, D. Kong et al., "Failure mechanism and grouting reinforcement technique of large mining height coal wall in thick coal seam with dirt band during topple mining," Journal of Mining \& Safety Engineering, vol. 31, no. 6, pp. 831-837, 2014.

[15] J. C. Wang, "Mechanism of the rib spalling and the controlling in the very soft coal seam," Journal of China Coal Society, vol. 32, no. 8, pp. 785-788, 2007.

[16] L. R. Alejano, P. Ramírez-Oyanguren, and J. Taboada, "FDM predictive methodology for subsidence due to flat and inclined coal seam mining," International Journal of Rock Mechanics and Mining Sciences, vol. 36, no. 4, pp. 475-491, 1999.

[17] Y. Yuan, S. H. Tu, Q. Wu, M. Xiaotao, T. Hongsheng, and S. Lulu, "Mechanics of rib spalling of high coal walls under fully-mechanized mining," Mining Science and Technology (China), vol. 21, no. 1, pp. 129-133, 2011.

[18] D. Z. Kong, S. L. Yang, L. Gao et al., "Determination of support capacity based on coal face stability control," Journal of the China Coal Society, vol. 42, no. 3, pp. 590-596, 2017.

[19] Y. N. Zhang, J. X. Tang, J. Y. Teng et al., "Research on mechanical properties specimens under consolidation of polymer materials and reinforcement," Journal of Mining \& Safety Engineering, vol. 35, no. 2, pp. 402-409, 2018.

[20] X. B. Meng, Soil Mechanics Course, Vol. 8, Peking University Press, Beijing, China, 2011.

[21] Z. Y. Chen, The Soil Slope Stability Analysis-Theory Methods and Programs, China WaterPower Press, Beijing, China, 2003.
[22] Y. S. Fang, "The lowest solution of slice method for slope stability analysis," Chinese Journal of Geotechnical Engineering, vol. 30, no. 3, pp. 331-335, 2008.

[23] Z. Y. Wu, J. K. Chen, W. L. Xu et al., "Research on methodology of reliability analysis of high rockfill dam slope stability using nonlinear strength indexes and its engineering application," Chinese Journal of Rock Mechanics \& Engineering, vol. 28, no. 1, pp. 130-137, 2009.

[24] F. Zhang, Y. Gao, Y. Wu et al., "Upper-bound solutions for face stability of circular tunnels in undrained clays," Géotechnique, vol. 69, no. 7, pp. 655-658, 2019.

[25] J. Ji, C. Zhang, Y. Gao, and J. Kodikara, "Reliability-based design for geotechnical engineering: an inverse FORM approach for practice," Computers and Geotechnics, vol. 111, pp. 22-29, 2019.

[26] P. J. Yang, C. Y. Liu, and F. F. Wu, "Breakage and falling of a high coal wall in a thick mined seam," Journal of China University of Mining \& Technology, vol. 41, no. 3, pp. 371-377, 2012.

[27] B. Xu, "Application of comprehensive geophysical-geochemical method in toudaoyingzi gold field," Journal of Liaoning Technical University (Natural Science), vol. 6, pp. 826-829, 2011.

[28] J. S. Li, Q. Z. Tian, and S. S. Yang, "The research on coal wall caving mechanism with stoop \& topple mining in coal caving mining face," Journal of Taiyuan University of Technology, vol. 4, pp. 407-409, 2004. 


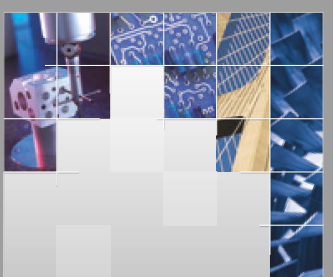

\section{Enfincering}
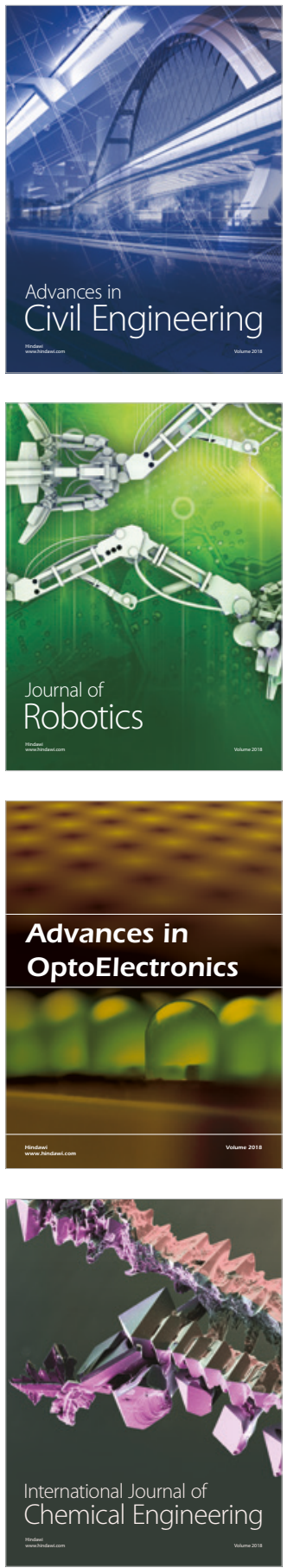

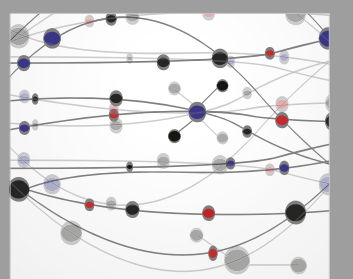

\section{Rotating \\ Machinery}

The Scientific World Journal

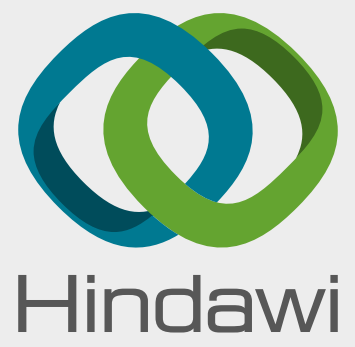

Submit your manuscripts at

www.hindawi.com
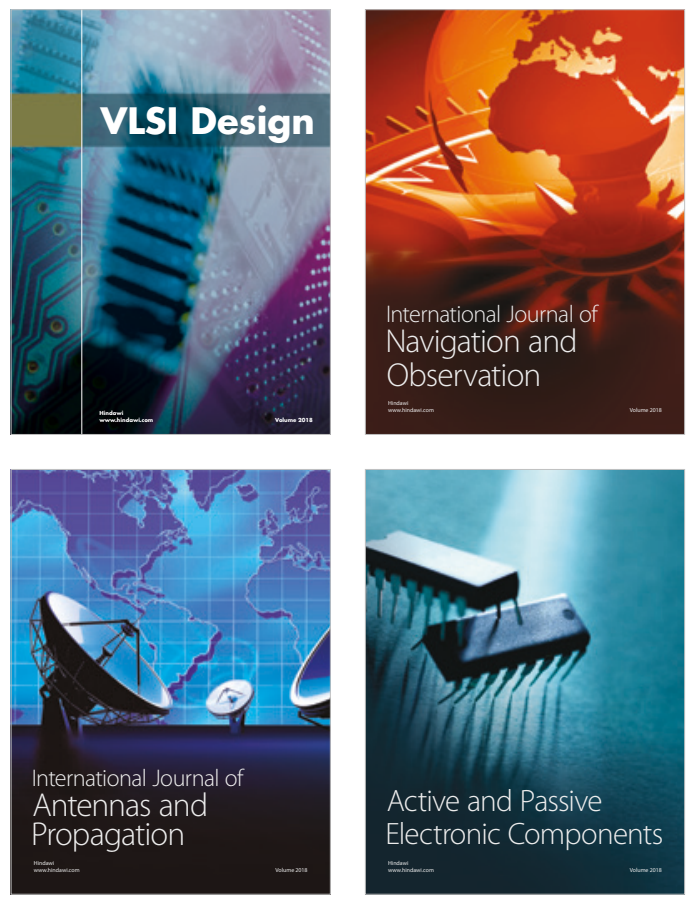
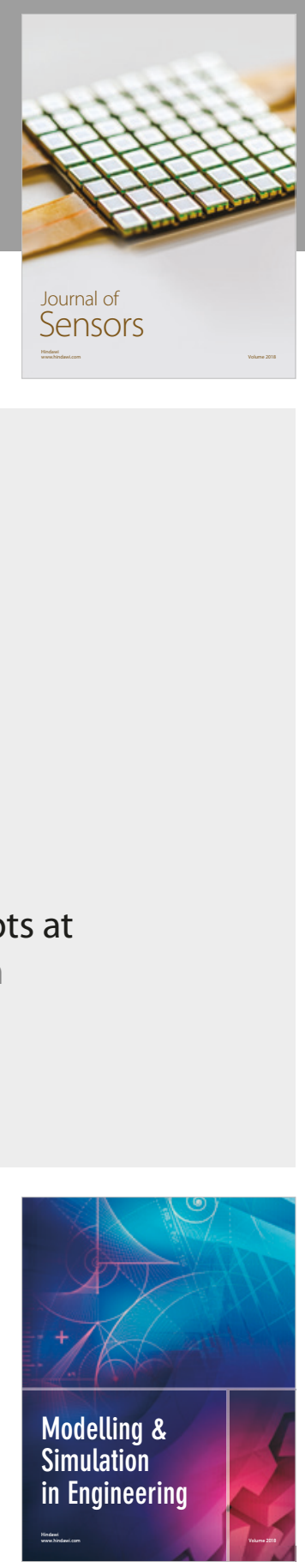

\section{Advances \\ Multimedia}
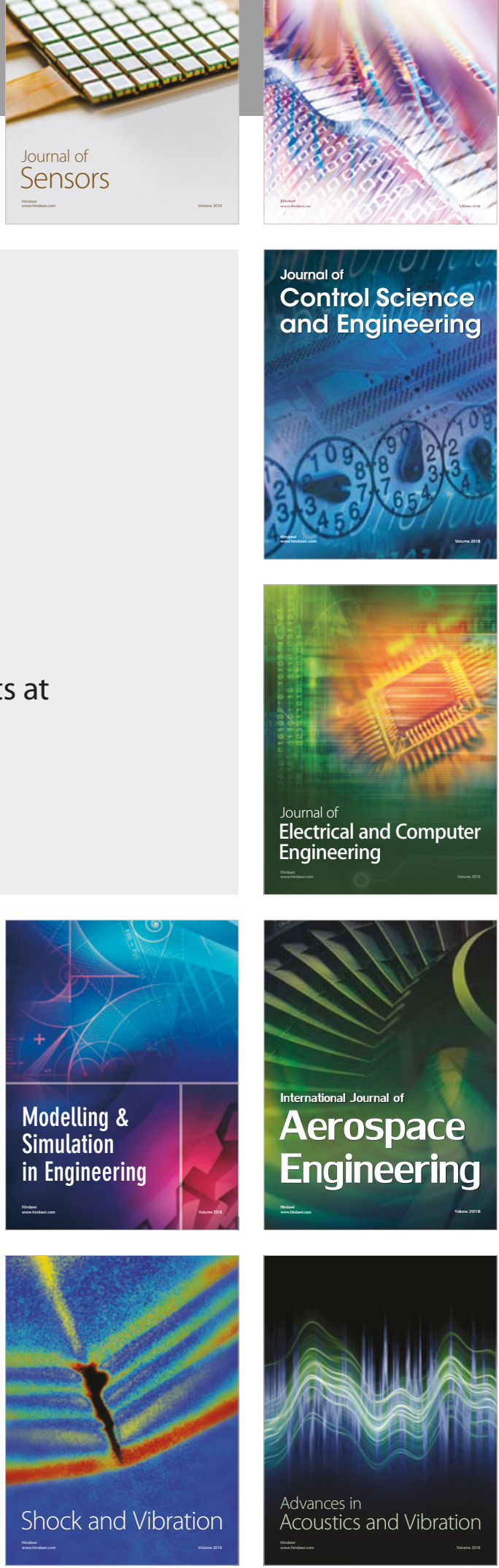